\title{
Importance of Water Chemistry in Oil and Gas Operations-Properties and Composition
}

\author{
Abdullah Taha, Mahmood Amani \\ Texas A \& M University at Qatar, Doha, Qatar \\ Email: mahmood.amani@qatar.tamu.edu
}

How to cite this paper: Taha, A. and Amani, M. (2019) Importance of Water Chemistry in Oil and Gas OperationsProperties and Composition. International Journal of Organic Chemistry, 9, 23-36. https://doi.org/10.4236/ijoc.2019.91003

Received: January 26, 2019

Accepted: February 23, 2019

Published: February 26, 2019

Copyright $\odot 2019$ by author(s) and Scientific Research Publishing Inc. This work is licensed under the Creative Commons Attribution International License (CC BY 4.0).

http://creativecommons.org/licenses/by/4.0/

(c) (i) Open Access

\begin{abstract}
In the oil and gas industry, water is essential element since it exists in most of the stages, starting from drilling operations, then production processes including injecting in the reservoir to maintain the pressure, and finally disposing the produced water from the reservoir. Therefore, it is very important to understand the water in the petroleum industry with its different types and study its effects on the reservoirs as well as the downhole and surface equipment. Most of the studies and literature reviews focused on the oil and gas properties. In fact, understanding the properties of the water is as important as the oil and gas properties. Water is always present in the oil and gas fields during production, injection or disposal. Therefore, it has a direct impact on the productivity and overall efficiency of the field and the entire development project. This paper is going to illustrate and focus on several objectives. First, it elaborates the importance of the water in the oil and gas fields. Then, it includes a comprehensive overview of different types of water in the petroleum industry including a summary about of their properties. The main two types that the paper focuses on are the produced water and the injected water. It clarifies the effects of both of them on the reservoir, well completions and facilities. After that, the paper touches bases on the common problems and issues caused by water along with a brief summary of steps needed by the operators to follow in order to solve them. In addition to that, the common monitoring procedures and tests that are usually followed to observe the quality of the water are going to be presented. Finally, couples of solutions used by operators are reviewed to solve the problem of excessive water production after the water breakthrough in the field.
\end{abstract}

\section{Keywords}

Reservoir Water, Water Injection, Breakthrough, Properties, Scale, Formation Volume Factor 


\section{Introduction}

Oil and gas industry depends heavily on water in many different aspects. Wherever there is oil or gas production, water is present. Therefore, understanding the properties and composition of the water in petroleum industry is essential. Unfortunately, water in petroleum industry does not get as much attention as the hydrocarbon fluids from researches and studies efforts. Water is a two edged sword. It can enhance the production and profitability of the development plan or be a direct reason of losing production and effectiveness of the investments.

Excessive water production is one of the main well-known problems that faces most of the oil operators worldwide in the hydrocarbon industry. Although it is a classic difficulty that occurs in old developed fields, it can happen in new ones too [1]. It causes numerous economic problems to the oil and gas production companies. First, excessive water affects the performance of the production wells and shorten their life period. The presence of the water in the wellbore increases the weight of the fluid column, which leads to an increase in the lifting requirements. That increases the operating cost and leads to a lower drawdown. For example, if the well is a gas lifted, the amount of gas injected to lift the fluid column from the wellbore to the surface is higher with the production of excessive water than without producing it. Water production also enhances the presence of scales, corrosions and degradation in the field facilities starting from the wellbore completions to the surface facilities [2]. Another major problem is the cost of separating, treating and disposing the produced water, which is a great burden over the oil company budgets. It costs around $\$ 1$ Billion/year in Alberta to dispose the produced water [3] getting rid of those kind of problems help in reducing expenses for the operators and increase the profitably of their operations [4].

On the other hand, water is one of the most important drives for oil production since it helps in managing the pressure of the reservoir, mobilizing the oil and displacing it in the homogenous rocks. This water is known by necessary or good water production. This water is typically associated with oil production in the late stages of water-flooding operations or from active aquifers. It is also the water produced at a low Water Oil Ratio (WOR) which maintain the profitably of a production well [1]. Attempts to reduce this kind of water production leads directly to reduction in the oil production [5]. On the contrary, the un-wanted water production is the type, which needs to be eliminated and reduced in order to increase the productivity and the profitability of the production wells [6]. Operators focus on eliminating unwanted water production, which is also named as Bad Water. This kind of production creates problems, other than the mentioned previously, such as losing oil production and poor sweep efficiency within the matrix rocks. That means simply, losing money! The worst problem among unwanted water production issues is the un-swept areas and oil pockets that are left behind as a result of bad conformance jobs. This case is commonly known in water-flooding operations where water is simply injected through injection wells 
to displace hydrocarbons toward the production wells and maintain the pressure of the reservoir. In many cases, the water goes to an open fracture or high permeability layer since it is all about the resistance of the paths in the reservoirs. The least resistance path is the winner in attracting the injected water toward it and the oil in the matrix rock stays behind without achieving the required sweep to attain efficient oil sweeping or good conformance [3]. If the production well happens to be connected to the open fracture or the high permeability layer, unwanted water production would occur. It is essential to be able to differentiate between those two types of water production in order to maintain the productivity of the well. One of the ways to identify the type of the excessive water production in a certain well is by studying the offset wells water cut behavior. It is a bad water production if the offset wells are producing with much lower water cut [4].

As mentioned previously, many reservoirs worldwide are water drive. In addition, operators use water to provide pressure support artificially to the production by injecting it into the reservoir. That gives us two main kinds of water in the petroleum industry, Produced water and Injected water. Their properties and composition can contrast broadly. Water presence can be also a nightmare for the operators. Water is the main source of scale deposits and corrosion that occurs in the upstream and downstream equipment. For the reservoir, it can form emulsion, creates skin and plug the formation. Those problems caused by water usually lead to huge expenses and reduce the profitability of the operation. That can be controlled if operators understand the properties of the water in their field and take pro-active steps to minimize the damage caused by water to the facilities and the reservoirs.

\section{Types of Water in Petroleum Industry}

As water is vital in all aspects of our life, it is also an important element in the oil and gas industry. Water is a great drive energy source that helps in sweeping the hydrocarbons from the reservoir to the wellbore of the production wells. There are two main types of water in the petroleum industry, Reservoir water and Injection water.

\subsection{Reservoir Water}

Reservoir water is defined as the water produced along with oil and gas production processes. Produced water has a lot of variations and properties. The source of the produced water is one of the variations, either it is connate or formation water. Another variation is the precipitations, contaminants, dissolved solids coming along with the produced water. In addition, the $\mathrm{p} \mathrm{H}$ levels that can be identified along with the previous mentioned variations from typical testing methods in the oil and gas industry. Clearer vision of the properties of the produced water is usually developed after drilling several wells in the field and identifying the drive mechanism as well as the boundaries and dimensions of the reservoir. 
Understanding reservoir water properties is essential part of studying the feasibility of developing an oil or gas field. Water production can promote scale, corrosion and plugging issues that require special completions, tools and inhibitor injection to cure and eliminate such issues. In addition, produced water handling facilities are required to handle the separated water, treat it and either dispose it in disposal wells or re-inject it into the reservoir thorough water injection wells to provide pressure support to the formation. All those aspects and more can increase the overall cost significantly and affect the profitability of developing an oil or gas field.

Initially, reservoir waters are in solution with hydrocarbons in the reservoir. That combination of fluid is trapped in a certain pressure and temperature. Hydrocarbons in the formation remain saturated with the water until the production operations kicks off. Normally, reservoir rocks surfaces are coated with water, or as described in the petroleum industry as water-wet rock [7]. Adding to that the compaction forces from the sedimentary basins that lead to natural drive allowing the fluid to flow from the reservoir to the wellbore once the well is drilled into the formation. To make it easier for the reader to imagine, the hydrocarbon formations can be simplified to be like a closed bottle of water under some sort of pressure. Once a hole is made in the bottle or the cape is open, the water starts to flow. As the production operations start, pressure and temperature drop and water changes from solution to free produced water coming along with the hydrocarbons. That drop in pressure occurs due to the lower pressure in the wellbore compared to the reservoir pressure, which initiates the production operation and drive the hydrocarbons from the formation to the wellbore and finally to the surface facilities. Usually in early stages of hydrocarbon production, water is produced in the form of emulsion in a relatively small volume that is separated in the separators or surface tanks without any need of emulsion treatment. The source of this water is usually coming from the connate water zones [8].

With more production, the pressure continues dropping and allowing the production of formation water along the transition zone, which starts from the connate zone to the oil water contact in the water drive reservoirs. Produced water in this case is a mixture between the connate water and the formation water that leads toan increase in the water cut in the production wells. At later stages, water breakthrough happens, especially from aquifers or nearby water injection wells. The water production can increase also due to water conning. Water conning is a common problem especially in gas wells that are completed deep in the formation to increase the recovery of the gas from the reservoir (Figure 1).

\section{Properties of Reservoir Waters [9]}

As mentioned previously, water is present wherever there are hydrocarbons deposits. Therefore, it is essential to understand the properties and the composition of reservoir waters. Reservoir waters usually are connate and formation 


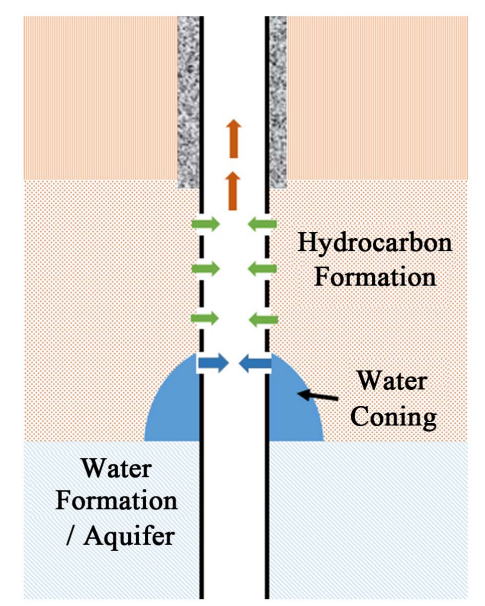

Figure 1. Water coning in the wellbore.

water. Brine is the most famous synonym for reservoir water in the oil and gas industry. The reason behind that is due to the dissolved solids that are always present in the formation water in different concentrations, which is mainly sodium chloride $(\mathrm{NaCl})$. Brine has higher solids concentrations and different ions distribution if compared to seawater. Usually, solids concentrations of formation water are counted as how many grams of solid in million grams of formation water which is known as parts per million ( $\mathrm{ppm}$ ). The solids in brine form from different elements and the most common elements in formation water are Sodium (Na), Calcium (Ca), Magnesium ( $\mathrm{Mg}$ ), Chlorine $(\mathrm{Cl})$, Sulfate $\left(\mathrm{SO}_{4}\right)$, Bicarbonate $\left(\mathrm{HCO}_{3}\right)$. There are other elements that are less common to form the solids in the brine like; Potassium (K), Barium (Ba), Lithium (Li), Iron ( $\mathrm{Fe})$, Strontium ( $\mathrm{Sr})$, Bicarbonate $\left(\mathrm{HCO}_{3}\right)$, Carbonate $\left(\mathrm{CO}_{3}\right)$, Nitrate $\left(\mathrm{NO}_{3}\right)$, Bromine $(\mathrm{Br})$, Iodine (I), Borate $\left(\mathrm{BO}_{3}\right)$ and Sulfur $(\mathrm{S})$. All of those elements dissolved in brine as cations and anions as shown below in Table 1. The concentrations of dissolved salts vary between different formation water based on the nature of formation and the surrounding factors. Therefore, reservoir waters always differ in composition even when compared with nearby reservoirs.

Other organisms can be also found in the brine such as bacteria, especially anaerobic sulfate reducing bacteria. Those microorganisms considered as one of the main factors behind corrosion and plugging in the reservoirs when introducing the water flooding to the formations and field facilities.

Another important property of brine is the bubble-point pressure. The bubble-point pressure is the pressure value that the first bubble of dissolved gas is released and starts leaving the fluid to travel to the wellbore or into the pore spaces of the formation. Usually, bubble-point pressure values of both water and oil in the same formation are equal due to the equilibrium between the two fluids in the formation. That property contributes directly to another main property, which is the formation volume factor of reservoir water $\left(B_{w}\right)$. This property represents the volume difference of formation water in the reservoir conditions and it is volume when produced to the surface. In other words, it is how many 
Table 1. Dissolved cations and anions in brine.

\begin{tabular}{cc}
\hline Cations & Anions \\
\hline Sodium $\left(\mathrm{Na}^{+}\right)$ & Chlorine $\left(\mathrm{Cl}^{-}\right)$ \\
Calcium $\left(\mathrm{Ca}^{2+}\right)$ & Sulfate $\left(\mathrm{SO}_{4}^{2-}\right)$ \\
Magnesium $\left(\mathrm{Mg}^{2+}\right)$ & Bicarbonate $\left(\mathrm{HCO}_{3}^{-}\right)$ \\
Potassium $\left(\mathrm{K}^{+}\right)$ & Carbonate $\left(\mathrm{CO}_{3}^{2-}\right)$ \\
Barium $\left(\mathrm{Ba}^{2+}\right)$ & Nitrate $\left(\mathrm{NO}_{3}^{-}\right)$ \\
Lithium $\left(\mathrm{Li}^{+}\right)$ & Bromine $\left(\mathrm{Br}^{-}\right)$ \\
Iron $\left(\mathrm{Fe}^{2+}\right)$ & Iodine $\left(\mathrm{I}^{-}\right)$ \\
Strontium $\left(\mathrm{Sr}^{2+}\right)$ & Borate $\left(\mathrm{BO}_{3}^{3-}\right)$ \\
& Sulfur $\left(\mathrm{S}^{2-}\right)$ \\
\hline
\end{tabular}

reservoir barrels of formation water are equivalent to a barrel of the same formation water on the surface. Pressure and temperature are the main factors controlling the formation volume factor of water in hydrocarbon formations. As the fluid is produced from the formation to the surface, the pressure is reduced. As a result, the water expands and increase in volume. At the same time, pressure reduction encourages the dissolved gas to be released form the formation water. As a result, the volume of the water decreases and offsets the expansion from pressure reduction. Likewise, as the fluid is transported from the formation to the surface, the temperature drops and effects the contraction of the water. However, unlike the oil, the solubility of gas in brine is much lower and the effects of contraction offsets the effects of the expansion. Therefore, brine formation volume factors values are usually approximately around one-reservoir barrels per surface barrel at standard conditions or one res bbl/STB.

Figure 2 shows the change of formation volume factor value of brine as the fluid travels from the formation to the surface with a decrease in the pressure, starting from the reservoir pressure, then bubble point pressure, and finally the pressure at the surface. This figure assumes constant reservoir temperature for illustration purposes. Prior bubble point pressure, the volume of formation water expands relatively faster with reduction of pressure. Once pressure is equal to the bubble point value, the expansion of the volume is lower due to dissolved gas migration from fluid and effects of that on losing overall volume of the fluid. However, the pressure reduction effects are relatively greater than gas migration effects. Therefore, surface barrel is relatively larger than reservoir barrel of brine. Since there is a bubble point pressure in the formation water, isothermal compressibility coefficient exists in it but lower than oil values. Another factor that controls the behavior of water formation factor is the concentrations of solids dissolved in it. Formation water with high solids concentration tends to have lower ability to dissolve gases, which leads to slight difference in the expansion behavior due to pressure reduction. Likewise, thermal expansion coefficient increase with higher solids content. 


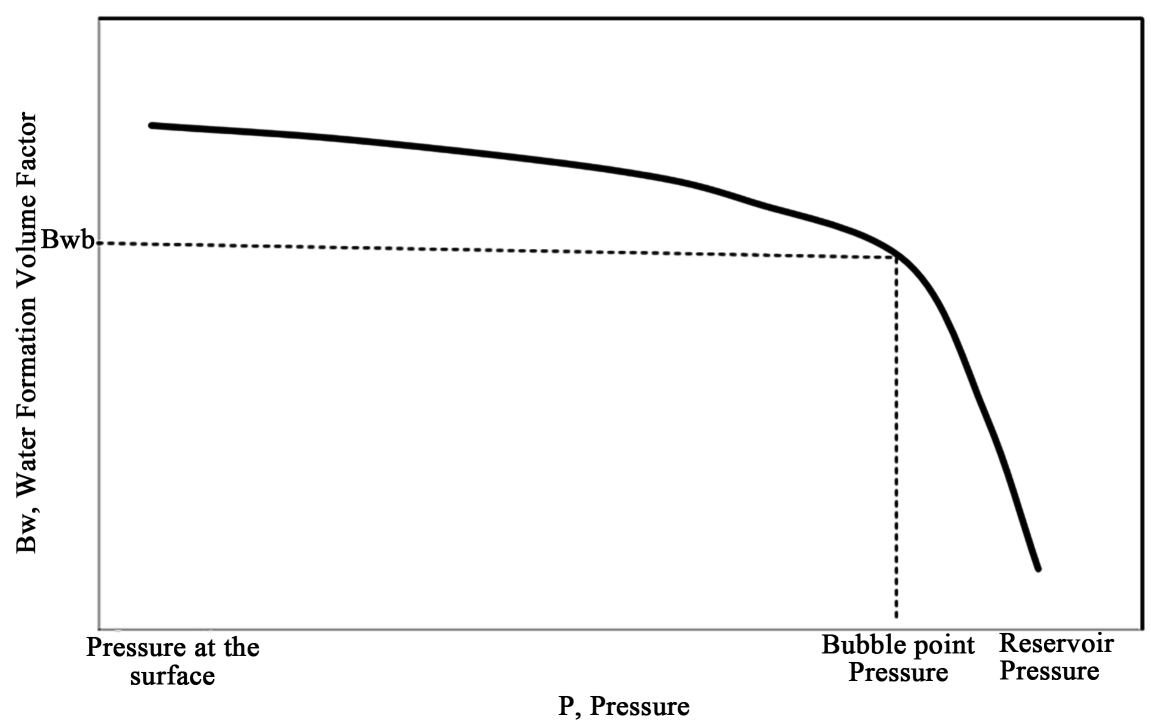

Figure 2. Sample of brine formation volume factor.

Concentrations of solids in formation water also lead to density estimation when dividing it by formation volume factor of water. Then from density, specific gravity can be defined. Regarding viscosity, formation water tends to have low viscosities unlike oil. Finally, formation water is conductive to electricity due to the solids dissolved in it, especially sodium chloride $(\mathrm{NaCl})$. Therefore, the resistivity values of formation water are usually low compared to hydrocarbons values. That property helps in indicating and differentiating between hydrocarbons zones and water zone while drilling wells by using resistivity tools.

For natural gases, the lighter the paraffin component, the more soluble it is in the formation water. In addition, pressure tends to effect more on the solubility of lighter paraffin natural gases than the heavier ones in the brine. On the other side, water solubility in natural gas depends on multiple factors such as the composition of the natural gas itself and the amount of dissolved solids in the water. Water is more soluble in natural gases with high carbon dioxide $\mathrm{CO}_{2}$ and hydrogen sulfide $\mathrm{H}_{2} \mathrm{~S}$. On the contrary, water with high solids content is lower in solubility with natural gases. Finally, solubility of water in liquid hydrocarbon is minor due to low mutual attraction among them.

Another common property of oilfield water is forming solids structures with natural gases in a certain temperature higher than water freezing temperature and pressure values that usually happens in the pipelines and surface facilities. This phenomenon is known as gas hydrates. It is also known as clathrate hydrates and it look like ice in the shape. The presence of water is necessary to form the gas hydrates. Inhibitors such as glycol and methanol are widely used by operators to prevent the gas hydrate from forming in the pipelines.

\subsection{Injection Water [8]}

Water flooding is the most common practice in reservoir management that is used by operators to enhance the overall recovery of the field. It is simply inject- 
ing water using injector wells that are drilled following certain pattern depending on the reservoir characterizations and boundaries. The injected water mainly compensate the loss of pressure occurring due to production operation and act as a drive to push the hydrocarbons toward the producer wells. On the other hand, water injection can be the source of many serious issues and problems to the field, wells and overall operation. Injected water, if not compatible or treated well, can form scales inside pipes and cause corrosion as well. It can also plug the formation if it contains solids or other types of plugging elements. Water used in the water flooding operation has to be free of oxygen and corrosive elements to avoid corrosion in the pipelines. In addition, the solids dissolved in the water has to be minimal to avoid scaling precipitations. Furthermore, injection water has to be filtered from contaminants to avoid plugging the formation. Finally, it is preferable to maintain the $\mathrm{pH}$ of the injected water in the range of 6.5 to 7.5. Therefore, sources of the water that are used in injection operations have to be compatible or treated enough to avoid those kind of problems that can strongly decrease the profitability of the development projects. Before discussing the problems caused by water injection, let us define the different types of water source used in injection operations in the petroleum industry. There are typically five different sources of injected water and they are from either Surface, Shallow, Deep, Sea or Produced Water. Sometimes a mixture is considered as a source of water to be injected.

Surface water is the water injected from rivers and lakes. It is not preferred in the petroleum industry because of the high content of the solids that cause plugging issues and the high corrosion occurring due to the high content of oxygen in it. Therefore, major treatment and filtration is needed prior injected surface water.

Shallow and deep water usually come from water reservoirs and aquifers. Obviously, the difference between them is the depth of the aquifer. In addition to that, usually the deeper the aquifer, the higher chloride content or higher salinity the water would be. Corrosion is not considered an issue with those two sources since they are typically oxygen free. However, with long-term projects, oxygen might find its way to the injected water through surface facilities and valves causing minor corrosion issues.

Seawater is the most common source for offshore operations and the most convenient. Many offshore development projects have seawater as the only source for water injection operations. Depending on the depth of the sea/ocean, quality of injected water differs. Water coming from shallow sea depth has the same properties and issues of surface water such as solids and oxygen content. The deeper source of the water, the higher quality it is. In most of the cases, scavenging the oxygen and solids filtering is required before injecting the water.

Produced water is another source for water injection that is coming from the water produced along with the hydrocarbons from production wells. This type is a burden to the operators. It is considered as the lowest quality type of water if compared to other injection water sources. It requires several treatments due to 
oil, solids, $\mathrm{CO}_{2}, \mathrm{H}_{2} \mathrm{~S}$ contents. Last type is the mixed water. It is a mixture of injection water with produced water from early stages of development of the field before water breakthrough. The produced water in this case has less solids and gas content since it is coming from the transition zone. However, once the water breakthrough occurs, there is no difference between it and the produced water properties.

Regardless the source of the water injection, evaluation has to be done to insure compatibility of the injected water with the reservoir. In addition to that, preparation of the essential processing equipment and chemicals has to be accomplished as well as evaluating the overall economics of the water flooding operation. The extension of evaluation depends on the size of the operation and the field as well. The bigger the reservoir, the more detailed investigation is required. Initially, water quality has to be tested to determine the volume of filterable solids in the injected water as well as the flow rate, which is usually done by using 0.45 microns pore size and $47 \mathrm{~mm}$ diameter filters. That test is also important to account for the injectivity of the water in the formation. In addition to that, it can help in determining the plugging rate. Another important type of tests are water corrosivity, scaling of water, clay swelling and content of sulfate reducing bacteria. Those tests are essential to install the proper equipment, account for needed inhibitors and avoid costly interventions during the operations.

\section{Associated Problems with Water in Petroleum Industry} [8]

As mentioned previously, beside the water being an essential element in the developments of petroleum fields, it can cause serious issues and problems compromising the profitability and the feasibility of the development projects. In this section, two main problems are briefly described to give the reader a quick overview about each of them. Each one need an extended research study to be fully explained from all aspects. Those two problems are corrosion and scaling.

Corrosion is considered as one of the main reasons behind the failures of injection equipment and pipelines. This occurs due to several factors such as the content of oxygen $\mathrm{O}_{2}$, carbon dioxide $\mathrm{CO}_{2}$, hydrogen sulfide $\mathrm{H}_{2} \mathrm{~S}$ and microorganisms in the water. Flow velocity of the water can also be a cause of failures due to the metal loss especially in zones of turbulence. It is recommended to be proactive to avoid failures that can stop the operation and loss injection and production. Periodic inspections are needed to early detect areas of corrosion and help in eliminating the source of it. That can be as simple as visually inspecting the tools and valves periodically. Other methods are also used to inspect corrosion such as ultra-sonic, radiography, calipers and spools inspection. Those methods are considered as directs ways of measuring the corrosion. There are other indirect ways of detecting the corrosion. Those tests depend on sampling, corrosion coupons and special corrosion monitoring devices. They follow several methods such as iron count in the fluid and testing other properties such as resistance. 
Scaling is a well-known precipitation caused by water in the petroleum industry. Scales are crystals that usually form in the pipelines and wellbores especially near surface with reduction in pressure and temperature. They are directly responsible for causing reduction in production due to the decrease of the internal diameters in the production tubing and in many cases can cause a total plug. Mixing two different types of incompatible waters is the main reason behind scale forming, which is a common problem after the water breakthrough. The most common way to predict scale formation is by monitoring the salinity of produced water. That happens by testing the samples that are collected periodically from producer wells to check the chloride content. There are different types of scales that are common to form in petroleum industry:

1) Calcium Carbonate $\mathrm{CaCO}_{3}$

2) Gypsum $\mathrm{CaSO}_{4} \cdot 2 \mathrm{H}_{2} \mathrm{O}$

3) Anhydrite $\mathrm{CaSO}_{4}$

4) Barium Sulfate $\mathrm{BaSO}_{4}$

5) Strontium Sulfate $\mathrm{SrSO}_{4}$

6) Salt $\mathrm{NaCl}$

Calcium Carbonate $\mathrm{CaCO}_{3}$ is the most common scale and usually forms in huge bulks. The presence of carbon dioxide $\mathrm{CO}_{2}$ enhance the formation of this type of scale, especially with low pressure and high $\mathrm{p} \mathrm{H}$. It can be dissolved by pumping hydrochloric acid $\mathrm{HCl}$. Many operators use continues chemical injection in the production wells to prevent it from forming. Salt scales usually form due to high salty water and has similar factors for precipitation as the calcium carbonate. Other types of scales like Gypsum, Anhydrite, Barium Sulfate and Strontium Sulfate are less common to form if compared to the previous types. However, they are more serious and difficult to solve once they are formed. They are insoluble in acid and inhibitors do not work well with them in late stages. Therefore, inhibitors has to be pumped as early as possible to avoid precipitation of those kinds of scales.

\section{After Water Breakthrough}

Although water breakthrough leads to a rapid increase in water cut, up to $99 \%$, many wells remains operationally economical depending on the volume of production, oil and gas price, operational costs and water handling rates. However, many operators nowadays are focusing on delaying the water breakthrough by completing the wells smartly and applying some chemical or mechanical solutions to avoid high water cuts. Chemical solutions can be considered as a permeant solution for fixing the excessive water production but more risky. Examples for chemical solutions are like gel injection or polymer flooding. Gel injection, which is mainly made of water with small volumes of polymers and crosslinking chemical agents, is used to reduce the water oil ratio and increase the conformance of a certain pattern. That happens through the ability of the gel to reduce the permeability and block the open features and high permeability water 
zones. They are very effective in reducing the permeability of unwanted zones and proved their ability to improve the sweep efficiency and shutting-off the unwater water zones. Polymer flooding is used to increase the viscosity of the water and help in mobilizing and displacing the oil in the reservoir matrix rock. Usually it is applied in the reservoir far from the production wells through water injection wells. The usage of polymer flooding is very common among the oil operators and it can be prepared by dissolving the polymers in the injected water and injecting it through injection wells. There are other chemical techniques for water-shutoff operation such as resins, solid particles and foams which are also effective in obtaining better conformance and enhance the sweep efficiency [5].

Mechanical solutions are easier in execution and faster in achieving results. Some examples of mechanical solutions are packers, plugs and smart completions such as Inflow Control Valves (ICV) (Figure 3), Inflow Control Devices (ICD) (Figure 4 \& Figure 5) and Autonomous Inflow Control Valves AICD (Figure 6).

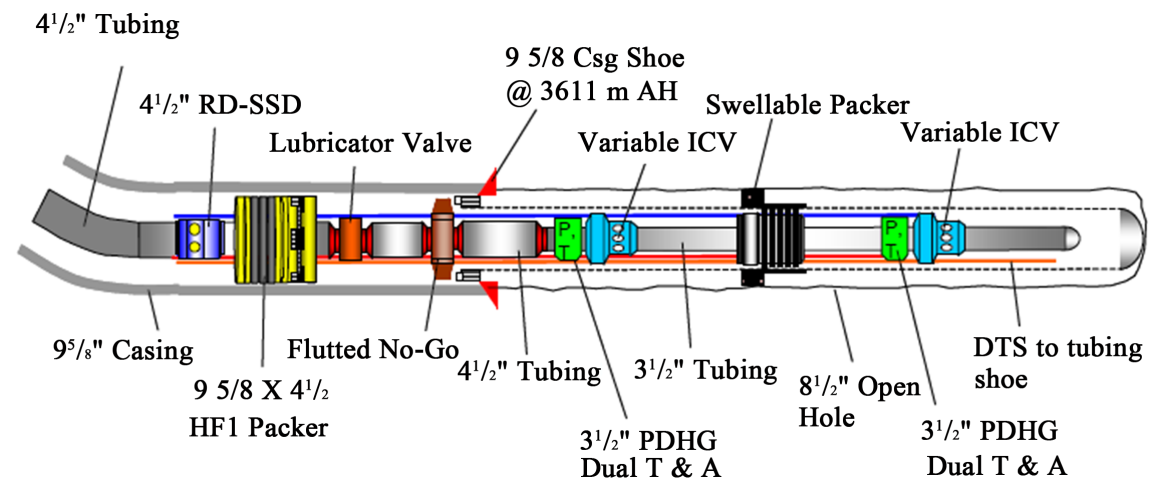

Figure 3. Example of ICV completion with swellable packers [10].

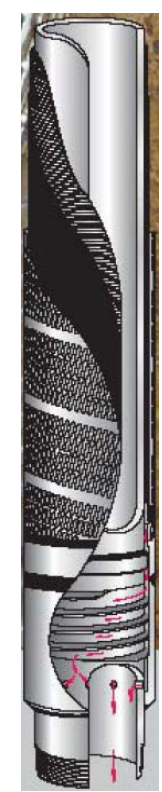

Figure 4. Inflow control device ICD [11]. 


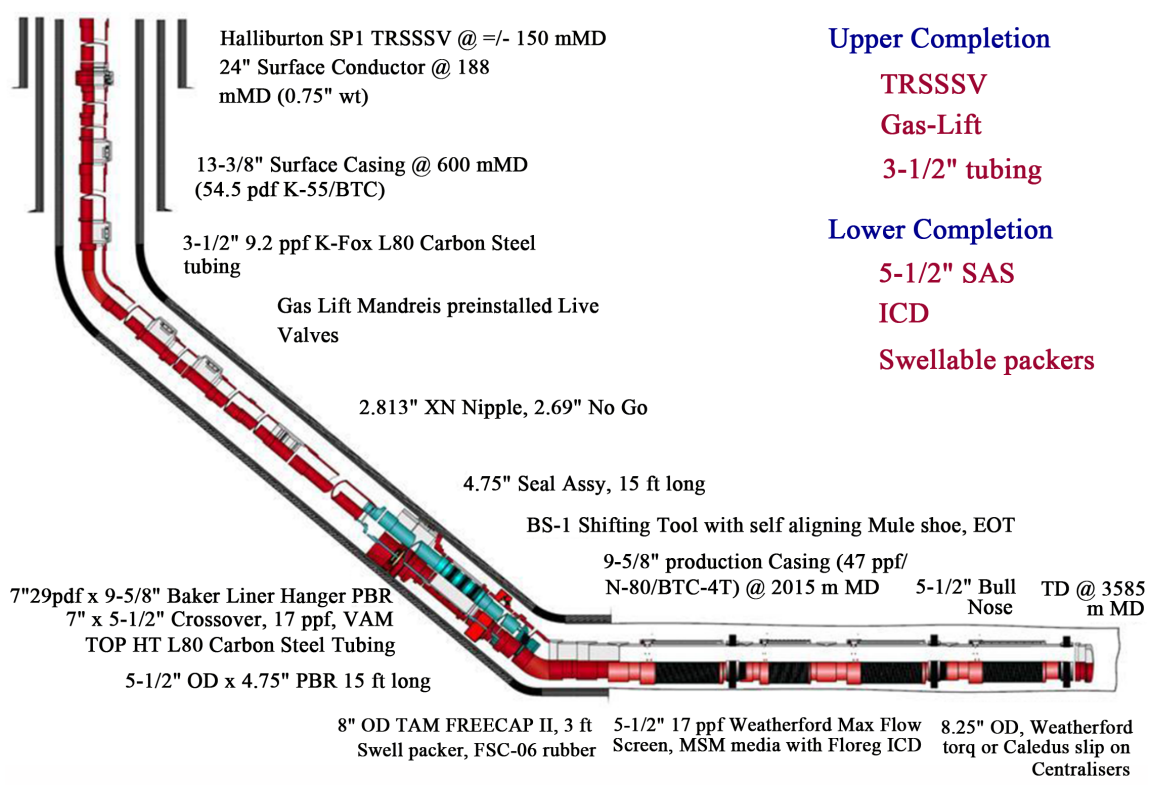

Figure 5. Example of ICD completion with Swellable packers [12].
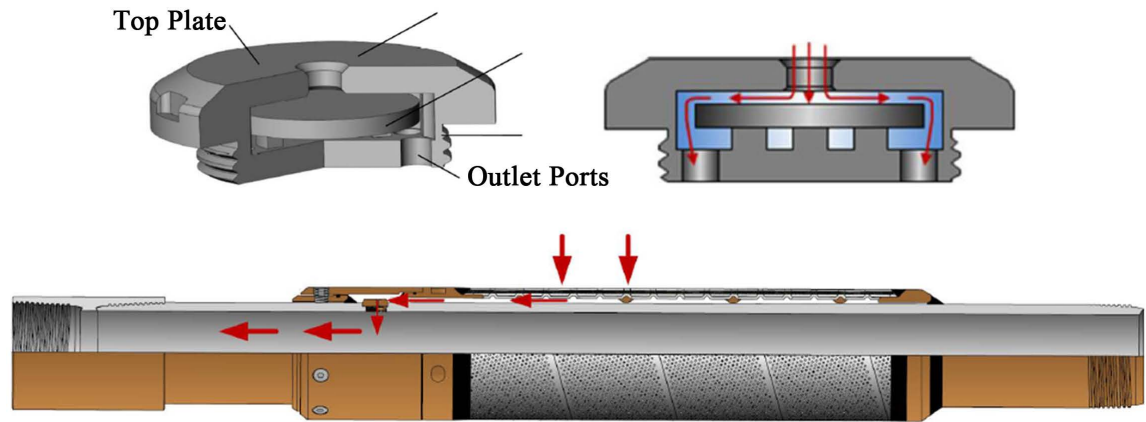

Figure 6. Autonomous inflow control valves (ACID) [13].

\section{Conclusion}

In conclusion, researchers are required to focus on studying water as much as studying the oil and gas. Water is vital element in the oil and gas industry. Therefore, it is very important to understand the different types and study their effects on the reservoir, the wells and surface equipment. Understanding the properties of the water is as important as the oil and gas properties. It has a direct impact on productivity and overall efficiency of the field and the whole development project. Water is the main source of scale deposits and corrosion that occurs in the upstream and downstream equipment. For the reservoir, it can form emulsion, creates skin and plug the formation; those problems caused by water usually lead to huge expenses and reduce the profitability of the operation. That can be controlled if operators understand the properties of the water in their field and take pro-active steps to minimize the damage caused by water to the facilities and the reservoirs. This paper reviewed the importance of the water in the oil and gas fields. Then, it illustrated the different types of waters in the petroleum industry including a summary about their properties. This paper ex- 
plains the effects of them on the reservoir, well completions and facilities. It also revises the famous problems and issues caused by water along with the steps needed by the operators to solve them as well as the common monitoring procedures and tests that are usually followed to observe the quality of the water. Further, this paper presents a couple of mechanical and chemical solutions used by operators which are used to solve the problem of excessive water production.

\section{Conflicts of Interest}

The authors declare no conflicts of interest regarding the publication of this paper.

\section{References}

[1] Joseph, A. and Ajienka, J.A. (2010) A Review of Water Shutoff Treatment Strategies in Oil Fields. The Annual SPE International Conference and Exhibition, Tinapa-Calaber, 31 July-7 August 2010. https://doi.org/10.2118/136969-MS

[2] Ahmad, N., Al-Shabibi, H. and Malik, S. (2012) Comprehensive Diagnostic and Water Shut-Off in Open and Cased Hole Carbonate Horizontal Wells. The Abu Dhabi International Petroleum Exhibition and Conference, Abu Dhabi, 11-12 November 2012.

[3] Thomas, F.B., Bennion, D.B., Anderson, G.E., et al. (2000) Water Shut-Off Treatments-Reduce Water and Accelerate Oil Production. Journal of Canadian Petroleum Technology, 39, 25-29. https://doi.org/10.2118/00-04-TN

[4] Permana, D., Ferdian, G., Aji, M., et al. (2015) Extracting Lessons Learned of 35 Water Shut-Off Jobs in Mature Fields to Improve Success Ration of Water Shut-Off Job. The SPE/IATMI Asia Pacific Oil \& Gas Conference and Exhibition, Bali, 20-22 October 2015.

[5] Sydansk, D. and Romero-Zeron, L. (2011) Reservoir Conformance Improvement. Society of Petroleum Engineers, Texas.

[6] Seright, R.S., Lane, R.H. and Sydansk, R.D. (2003) A Strategy for Attacking Excess Water Production. SPE Production \& Facilities, 18, 158-169. https://doi.org/10.2118/84966-PA

[7] Hirasaki, G.J. (1991) Wettability: Fundamentals and Surface Forces. Society of Petroleum Engineers. https://doi.org/10.2118/17367-PA

[8] Endean, H. and Shelton, R. (1991) Water Initiated Problems in Production Operations. Champion Technologies, Inc., Houston.

[9] McCain, W. (1990) The Properties of Petroleum Fluids. 2nd Edition, PennWellBooks, Tulsa.

[10] Obendrauf, W., Schrader, K., Al-Farsi, N., et al. (2006) Smart Snake Wells in Champion West-Expected and Unexpected Benefits From Smart Completions. The SPE Asia Pacific Oil and Gas Conference and Exhibition, Adelaide, 11-13 September 2006.

[11] Armenta, M., Al-Ghamdi, A. and Al-Hajji, A. (2007) Applications of Mechanical External Casing Packers. 15th SPE Middle East Oil and Gas Show and Conference, Manama, 11-14 March 2007. https://doi.org/10.2118/105380-MS

[12] Chan, K., Masoudi, R., Karkooti, H., et al. (2014) Production Integrated Smart Completion Benchmark for Field Re-Development. The International Petroleum Technology Conference, Doha, 20-22 January 2014. 
[13] Ahmad, F., Al-Neaimi, A., Saif, O., et al. (2016) Rejuvenating a High GOR, Light Oil Reservoir Using ACID Completion Technology for Gas Control. The Abu Dhabi International Petroleum Exhibition and Conference, Abu Dhabi, 7-10 November 2016. 